\title{
Deep brain stimulation for seizure control in drug-resistant epilepsy
}

\author{
Neil Klinger, MD, ${ }^{1,2}$ and Sandeep Mittal, MD, FRCSC1,2 \\ ${ }^{1}$ Department of Neurosurgery, Wayne State University; and ${ }^{2}$ Comprehensive Epilepsy Program, Detroit Medical Center, Wayne \\ State University, Detroit, Michigan \\ Antiepileptic drugs prevent morbidity and death in a large number of patients suffering from epilepsy. However, it is \\ estimated that approximately $30 \%$ of epileptic patients will not have adequate seizure control with medication alone. \\ Resection of epileptogenic cortex may be indicated in medically refractory cases with a discrete seizure focus in nonelo- \\ quent cortex. For patients in whom resection is not an option, deep brain stimulation (DBS) may be an effective means of \\ seizure control. Deep brain stimulation targets for treating seizures primarily include the thalamic nuclei, hippocampus, \\ subthalamic nucleus, and cerebellum. A variety of stimulation parameters have been studied, and more recent advances \\ in electrical stimulation to treat epilepsy include responsive neurostimulation. Data suggest that DBS is effective for treat- \\ ing drug-resistant epilepsy.
}

https://thejns.org/doi/abs/10.3171/2018.4.FOCUS1872

KEYWORDS medically refractory epilepsy; catastrophic epilepsy; brain stimulation; seizures; epilepsy surgery; responsive neurostimulation

$\mathrm{E}$ PILEPSY has an estimated lifetime prevalence of 7.6 cases per 1000 persons and an incidence of 68 cases per 100,000 individuals internationally. ${ }^{19}$ In the 2010 Global Burden of Disease Study, epilepsy was found to have a worldwide burden second only to migraine headaches among neurological disorders. ${ }^{48}$ The International League Against Epilepsy defines drug-resistant epilepsy as a failure to achieve sustained seizure freedom after two appropriately chosen, tolerated, and scheduled antiepileptic drugs (AEDs), whether they are given as monotherapy or in combination. ${ }^{35}$ Estimates of patients with drug-resistant epilepsy are as high as $30 \%$ but vary depending on the resistance criteria used and are generally slightly lower in more developed countries. ${ }^{53}$

The mechanism by which the disorder is resistant to AEDs remains incompletely understood. The most prevalent explanations include the "target hypothesis" and the "transporter hypothesis." In the target hypothesis, it is thought that changes in the AED targets, such as ion channels, lead to decreased drug efficacy. In contrast, in the transporter hypothesis, efflux pumps are thought to restrict AED movement into cells and to be overexpressed in patients resistant to AEDs ${ }^{61}{ }^{\mathrm{P}}$-glycoprotein (Pgp) is one such multidrug transporter that has been implicated in drug-resistant epilepsy. Significantly increased levels of Pgp have been found in patients with medically refractory epilepsy. ${ }^{18}$ Among patients with drug-resistant epilepsy, adding surgical treatment is four times more likely to result in seizure freedom than medical treatment alone. ${ }^{58} \mathrm{~A}$ meta-analysis of long-term ( $\geq 5$ years) seizure freedom after epilepsy surgery revealed that $66 \%$ of patients who underwent temporal lobe resections were seizure free, though this figure was lower among patients requiring extratemporal resection. ${ }^{62} \mathrm{~A}$ review of nine systematic reviews and two large case series of patients with intractable epilepsy revealed a median $62.4 \%$ of patients to be seizure free after epilepsy surgery; however, surgery was found to be less effective for epilepsy not associated with structural pathology and/ or extratemporal lesions. ${ }^{31}$ Better surgical outcomes were reported when seizures were associated with hippocampal

ABBREVIATIONS AED = antiepileptic drug; ANT = anterior nucleus of thalamus; $\mathrm{CMT}=$ centromedian nucleus of thalamus; $\mathrm{DBS}=$ deep brain stimulation; $\mathrm{ECOG}=$ electrocorticographic; RNS = responsive neurostimulation; SANTE = Stimulation of the Anterior Nucleus of the Thalamus for Epilepsy; STN = subthalamic nucleus; TLE = temporal lobe epilepsy; VNS = vagus nerve stimulation.

SUBMITTED February 9, 2018. ACCEPTED April 16, 2018.

INCLUDE WHEN CITING DOI: 10.3171/2018.4.FOCUS1872. 


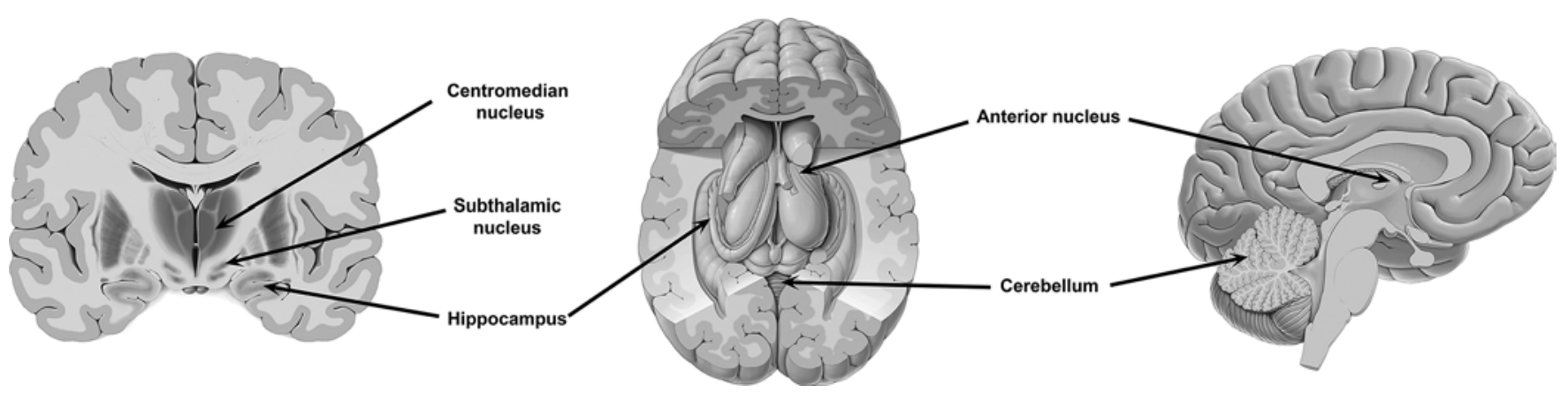

FIG. 1. Common targets for DBS in the treatment of epilepsy: thalamic nuclei (CMT, ANT), STN, hippocampus, and cerebellum.

sclerosis and benign tumors. Mortality with epilepsy surgery was reported to be $0.1 \%-0.5 \%$, and surgery is effective and safe for correctly selected patients.

In general, contraindications to epilepsy surgery include the lack of a discrete seizure focus, seizure foci involving eloquent cortex, or significant comorbidities such that the patient is not medically stable for resective surgery. For patients whose epilepsy is refractory to medical therapy and who are not good candidates for resective epilepsy surgery, other treatment options are available. Nonsurgical therapies that may reduce seizures in appropriately selected patients include the administration of a ketogenic diet and, to a lesser degree, the use of cannabidiol, although current data are conflicting as to their efficacies. ${ }^{17,49,72}$ Vagus nerve stimulation is less invasive than resective surgery and improves seizure control in carefully selected individuals. ${ }^{16,25,47}$ Deep brain stimulation (DBS) is another promising treatment modality that has shown efficacy in decreasing seizure frequency in patients with refractory epilepsy.

\section{Mechanism of Action and Preclinical Data}

Deep brain stimulation's mechanism of action in treating epilepsy remains poorly understood. Stimulation may, in fact, disrupt pathological network activity by reducing neuronal activity in the stimulated target. ${ }^{43}$ However, studies have shown complex patterns of excitation as well as inhibition with DBS..$^{40}$ Animal studies have demonstrated that high-frequency stimulation of the anterior nucleus of the thalamus (ANT) leads to cortical desynchronization and may be protective against seizures, whereas low-frequency stimulation provokes seizures. ${ }^{45}$ Rhythmic stimulation from DBS has been likened to a pacemaker that helps to synchronize thalamocortical networks and prevent the disorganized cortical spread thought to underlie seizures. ${ }^{33}$ The optimal stimulation parameters for any given DBS target are largely based on trial-and-error methodologies or the use of parameters that have been successful for other DBS targets. For example, some studies have demonstrated that the DBS current is more important than the stimulation frequency in pilocarpineinduced seizure models. ${ }^{24}$ However, the efficacy of hippocampal stimulation may be driven by the frequency of stimulation and may be independent of stimulation intensity. ${ }^{1}$
Some literature suggest that at least part of the efficacy of DBS may simply be attributable to the lesional effect

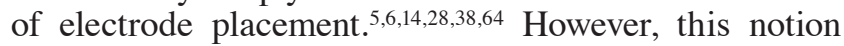
has been experimentally controlled for and debated by other groups. ${ }^{20,32,37,50,69}$ For example, a recent study examined nine patients with refractory epilepsy treated with DBS. ${ }^{13}$ These patients were followed up for changes in seizure rates after their stimulator battery had been depleted. Only two patients did not have changes in their seizure frequency, whereas seven $(78 \%)$ had increased seizure frequency. Interestingly, five of the seven individuals still reported a seizure frequency less than even their baseline before DBS, suggesting that a portion of, but not all, seizure relief is due to the lesional effect. Many structures have been the target of stimulation in human trials to improve seizure control (Fig. 1 and Table 1), including the ANT, 2,20,39,57,66 the centromedian nucleus of the thalamus (CMT), ${ }^{21,52,60,64,67}$ the cerebellum, ${ }^{4,65,69,75}$ the hippocampus, $, 5,14,15,30,68,73$ and the subthalamic nucleus (STN). ${ }^{10,26,36,71}$

\section{Common DBS Targets Studies on Targeting the ANT}

The ANT is divided into the anterodorsal, anteroventral, and anteromedial subnuclei, which all have distinct patterns of connectivity. These include widespread connections to the frontal lobes as well as to other members of the Papez circuit. The ANT receives inputs from the subiculum, the mammillary bodies via the mammillothalamic tract, and the retrosplenial cortex..$^{29}$ This local network has further diffuse cerebral connectivity, which likely underlies its therapeutic potential for seizure control. Most available data suggest that ANT DBS is most useful for the treatment of partial and secondarily generalized seizures.

The highest quality data supporting the use of ANT DBS comes from the Stimulation of the Anterior Nucleus of the Thalamus for Epilepsy (SANTE) trial. Results of this landmark multicenter, double-blind randomized study of bilateral ANT stimulation were reported in $2010 . .^{20}$ The study population consisted of patients ages 18-65 years with partial seizures, including secondarily generalized seizures, in whom at least three AEDs had failed. A criterion for study inclusion was seizures for at least 6 months, 
TABLE 1. Summary of studies using various targets for deep brain stimulation for intractable epilepsy

\begin{tabular}{|c|c|c|c|c|}
\hline Authors \& Year & No. & Target & Stimulation & Seizure Outcomes* \\
\hline $\begin{array}{l}\text { Fisher et al., 2010; Sala- } \\
\text { nova et al., } 2015\end{array}$ & 110 & Bilat ANT & $5 \mathrm{~V}, 90 \mu \mathrm{sec}, 145 \mathrm{~Hz} ; 1 \mathrm{~min}$ on $/ 5$ mins off & $69 \%$ \\
\hline Hodaie et al., 2002 & 5 & Bilat ANT & $10 \mathrm{~V}, 90 \mu \mathrm{sec}, 100 \mathrm{~Hz} ; 1 \mathrm{~min}$ on $/ 5$ mins off & $54 \%(24 \%-89 \%)$ \\
\hline Andrade et al., 2006 & 6 & Bilat ANT & $\begin{array}{l}1-10 \mathrm{~V}, 90-120 \mu \mathrm{sec}, 100-185 \mathrm{~Hz} \text {; continuous } \\
\quad \text { or } 1 \mathrm{~min} \text { on } / 4-5 \text { mins off }\end{array}$ & $\geq 50 \%$ in $5 / 6$ patients \\
\hline Kim et al., $2017^{34}$ & 29 & Bilat ANT & 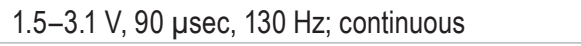 & $62 \%-80 \%$ after $3-11$ yrs \\
\hline Velasco et al., 1995 & 5 & Bilat CMT & $0.45-0.8 \mathrm{~A}, 90 \mu \mathrm{sec}, 65 \mathrm{~Hz} ; 1 \mathrm{~min}$ on/4 mins off & Near abolition of GTC; no change in CPS \\
\hline Fisher et al., 1992 & 7 & Bilat CMT & Variable, $90 \mu \mathrm{sec}, 65 \mathrm{~Hz} ; 1 \mathrm{~min}$ on $/ 4 \mathrm{mins}$ off & $30 \%$ \\
\hline Valentín et al., 2013 & 11 & Bilat CMT & $\leq 5 \mathrm{~V}, 90 \mu \mathrm{sec}, 60$ or $130 \mathrm{~Hz}$; continuous & $\begin{array}{l}6 / 6 \mathrm{w} / \text { generalized epilepsy responded; } 1 / 5 \mathrm{w} / \\
\text { focal epilepsy responded }\end{array}$ \\
\hline Son et al., 2016 & 14 & Bilat CMT & $2.2 \mathrm{~V}, 120 \mu \mathrm{sec}, 130 \mathrm{~Hz} ; 3$ mins on $/ 2$ mins off & $68 \%(25 \%-100 \%), 11 / 14$ responders \\
\hline Velasco et al., 2006 & 13 & Bilat CMT & $0.4-0.6 \mathrm{~A}, 450 \mu \mathrm{sec}, 130 \mathrm{~Hz} ; 1 \mathrm{~min}$ on $/ 4$ mins off & $80 \%$ \\
\hline Boon et al., 2007 & 10 & Bilat $\mathrm{AH}$ & 2-3 V, 450 usec, $130 \mathrm{~Hz}$; continuous & $7 / 10$ responders \\
\hline Boëx et al., 2011 & 8 & Unilat $\mathrm{AH}$ & $0.5-2 \mathrm{~V}, 450 \mu \mathrm{sec}, 130 \mathrm{~Hz}$; continuous & $4 / 6$ responders, 2 of whom were seizure free \\
\hline Cukiert et al., 2014 & 9 & Uni- or bilat HIP & $1-3.5 \mathrm{~V}, 300$ usec, $130 \mathrm{~Hz}$; continuous & $76 \%-80 \%$ (unilat), $66 \%-100 \%$ (bilat) \\
\hline Cukiert et al., 2017 & 16 & Uni- or bilat HIP & $2 \mathrm{~V}, 300 \mu \mathrm{sec}, 130 \mathrm{~Hz}$; continuous & $50 \%$ achieved seizure freedom; $88 \%$ responders \\
\hline Velasco et al., 2007 & 9 & Bilat HIP & $0.3 \mathrm{~A}, 300 \mu \mathrm{sec}, 130 \mathrm{~Hz} ; 1 \mathrm{~min}$ on $/ 4 \mathrm{mins}$ off & $50 \%-70 \%(\mathrm{HS}),>95 \%$ (NLMTLE) \\
\hline Tellez-Zenteno et al., 2006 & 4 & Unilat HIP & 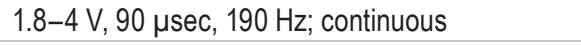 & $15 \%$ \\
\hline Chabardès et al., 2002 & 5 & Uni- or bilat STN & 1.5-5.2 V, 60-90 $\mu \mathrm{sec}, 130 \mathrm{~Hz}$; continuous & $64 \%$ in $4 / 5$ patients \\
\hline Lee et al., 2006 & 3 & Bilat STN & $0.8-3.2 \mathrm{~V}, 60 \mu \mathrm{sec}, 130 \mathrm{~Hz}$; continuous & $49 \%$ \\
\hline Handforth et al., 2006 & 2 & Bilat STN & $\leq 3.5 \mathrm{~V}, 60-90 \mu \mathrm{sec}, 130-185 \mathrm{~Hz}$; continuous & $50 \% \& 33 \%$ \\
\hline Vesper et al., 2007 & 1 & Bilat STN & $2.5-3 \mathrm{~V}, 90$ usec, $130 \mathrm{~Hz}$; continuous & $50 \%$ \\
\hline Van Buren et al., 1978 & 5 & Bilat $\mathrm{CH}$ & $10-14 \mathrm{~V}, 10-200 \mathrm{~Hz}$; continuous & No objective benefit \\
\hline Bidziński et al., 1981 & 14 & Bilat $\mathrm{CH}$ & $1-7 \mathrm{~V}, 10 \mathrm{~Hz}$; continuous & Seizure freedom in $5 / 14$; no benefit in $3 / 14$ \\
\hline Velasco et al., 2005 & 5 & Bilat $\mathrm{CH}$ & $2.28 \mathrm{~V}, 450 \mu \mathrm{sec}, 10 \mathrm{~Hz} ; 4$ mins on/4 mins off & $59 \%(25 \%-86 \%)$ \\
\hline Wright et al., 1984 & 12 & Bilat $\mathrm{CH}$ & $7 \mathrm{~mA}, 10 \mathrm{~Hz}$; intermittent \& continuous & No benefit \\
\hline Gwinn \& Morrell, 2017 & 175 & $\begin{array}{l}\text { Depth or subdu- } \\
\text { ral electrodes }\end{array}$ & $\begin{array}{l}\text { Commonly } 1.5-3.0 \mathrm{~mA}, 160 \mu \mathrm{sec}, 100-200 \mathrm{~Hz} \text {; } \\
\text { responsive stimulation }\end{array}$ & $73 \%$ \\
\hline
\end{tabular}

$\mathrm{AH}=$ amygdalohippocampus; $\mathrm{CH}$ = cerebellar hemisphere; $\mathrm{CPS}=$ complex partial seizure; $\mathrm{GTC}$ = generalized tonic-clonic seizure; HIP = hippocampus; $\mathrm{HS}=$ hippocampal sclerosis; NLMTLE = nonlesional mesial temporal lobe epilepsy.

* Except where noted, percentages indicate the mean or median percent reduction in seizure frequency from baseline. Ranges are noted in parentheses. Patients designated as "responders" indicate $\geq 50 \%$ reduction in seizure frequency.

but no more than 10 seizures per day. Patients with progressive neurological diseases were excluded, as were patients with nonepileptic seizures, those with an IQ $<70$, or those who were pregnant. Patients who had undergone prior vagus nerve stimulation (VNS) device implantation and/or resection (53.6\%) were allowed to enroll. A total of 110 patients underwent electrode implantation. After randomization, patients remained in the blind phase of the study for 3 months, then moved to a 9-month unblinded phase in which all patients received stimulation. During the blind phase, $36.3 \%$ of patients in the stimulation group experienced improvement in their complex partial seizures versus $12.1 \%$ of control patients who experienced improvement $(\mathrm{p}=0.041)$. In addition, injuries occurring as a result of seizures were lower in the stimulation group (7\%) than in the control group $(26 \% ; \mathrm{p}=0.01)$. Interestingly, patients previously implanted with a VNS device or who underwent resective surgery prior to DBS had outcomes that were not different from those in the patients who did not undergo these other procedures. Long-term results of the SANTE trial were published in 2015 and are even more compelling. ${ }^{57}$ At the 5-year follow-up, median seizure reduction from baseline was $-69 \%$, and participants had experienced a statistically significant increase in quality of life.

The results of many smaller unblinded trials have also been reported. In 2002, Hodaie et al. described the results of bilateral ANT DBS treatment in five patients with medically refractory epilepsy. ${ }^{28}$ They documented an average seizure reduction of $54 \%$ (range $24 \%-89 \%$ ) at a mean follow-up of 15 months, with two patients experiencing a $\geq 75 \%$ reduction in seizures. Similarly, Andrade and colleagues obtained at least a 50\% reduction in seizure frequency in five of six patients receiving ANT DBS. ${ }^{2}$ In a single-center prospective study, Kim et al. reported treating 29 patients with ANT DBS. ${ }^{34}$ They obtained a median seizure reduction of $71 \%$ at 1 year, $74 \%$ at 2 years, and $62 \%-80 \%$ from years 3 to 11 . 


\section{Studies on Targeting the CMT}

The CMT, together with the parafascicular nuclei, form the posterior group of the intralaminar nuclei of the thalamus. The motor cortex provides input to the CMT, as do the globus pallidus interna (GPi). The CMT projects back to the motor cortex as well as the striatum with particular preference for the putamen and the head of the caudate nucleus proximal to the internal capsule..$^{55}$ The majority of available data support the use of CMT DBS for the treatment of generalized epilepsy, including patients suffering from Lennox-Gastaut syndrome.

After publishing their preliminary results in 1987, Velasco et al. provided long-term follow-up data on bilateral CMT DBS in $1995 . .^{70}$ Five patients followed up between 7 and 33 months experienced near abolition of generalized tonic-clonic seizures. Interestingly, however, there was no reported change in the number of complex partial seizures. In a study published in 1992, Fisher and colleagues detailed the treatment of seven patients with intractable epilepsy using bilateral CMT DBS. ${ }^{21}$ They reported a $30 \%$ decrease in generalized tonic-clonic seizures with stimulation in the on mode versus $8 \%$ when the stimulator was off. In addition, three of six patients who entered the follow-up segment of the study experienced at least a $50 \%$ reduction in seizure frequency. Likewise, a two-center single-blind trial of CMT DBS in 11 patients reported that only one of five patients with frontal lobe epilepsy had $>50 \%$ improvement in seizure frequency, whereas all six patients with generalized epilepsy had such improvement. ${ }^{64}$ The authors concluded, as many other groups have, that CMT DBS may be more effective for patients experiencing generalized epilepsy. In a study of 14 patients with refractory epilepsy, Son et al. reported a mean seizure reduction of $68 \%$ (range $25 \%-100 \%$ ) at an average follow-up of 18.2 months. In total, 11/14 patients attained a $>50 \%$ reduction in their seizure frequency. ${ }^{60}$ Other patients with generalized seizures, such as those with Lennox-Gastaut syndrome, may have an improved response to CMT DBS. In another study by Velasco et al., 13 patients with Lennox-Gastaut were treated with bilateral CMT DBS. Overall seizure reduction was reportedly an astonishing $80 \% .{ }^{67}$

\section{Studies on Targeting the Hippocampus}

The hippocampus is an essential component of the mesial temporal lobe and the Papez circuit. It is formed from the dentate gyrus and the pyramidal layer, further divided into four zones labeled as cornu ammonis (CA) $1-4$. The perirhinal and parahippocampal cortices supply the entorhinal cortex, which also receives input from the amygdala, piriform cortex, insula, basal forebrain, frontal cortex, thalamus, brainstem, and basal ganglia. The entorhinal cortex in turn projects to the hippocampus. The Papez circuit continues by projections from the subiculum to the fornix, the mammillary bodies and mammillothalamic tract, the ANT, the cingulum, and back through the entorhinal cortex. ${ }^{59}$ There is further spread to the cerebral cortex through many of these structures. Deep brain stimulation to the hippocampus or other mesial temporal lobe structures has been focused on the treatment of mesial temporal lobe epilepsy (TLE).
Anterior temporal lobectomy or selective mesial temporal resection can lead to seizure freedom in $70 \%$ of patients. ${ }^{11}$ Approximately 30\% of patients with TLE are unsuitable for resection due to bilateral disease or concern for verbal memory loss after amygdalohippocampectomy, such as those with nonlesional left TLE. ${ }^{42} \mathrm{~A}$ report published in 2007 detailed a pilot study of 10 consecutive patients with refractory mesial TLE treated with amygdala-hippocampal DBS. ? Patients were followed up for an average of 31 months, and seven of the 10 patients experienced a seizure reduction of at least $50 \%$. A separate trial treated eight patients with drug-resistant epilepsy using amygdala-hippocampal DBS. ${ }^{5}$ The two patients with hippocampal sclerosis experienced a $65 \%-75 \%$ decrease in seizure frequency. Two of the remaining patients with nonlesional mesial TLE became seizure free.

In a 2014 study, Cukiert et al. treated nine patients with refractory TLE using hippocampal DBS. ${ }^{14}$ Patients with unilateral hippocampal sclerosis were treated with unilateral DBS and had a 76\%-80\% reduction in seizure frequency. Patients with bilateral hippocampal sclerosis $(n=4)$ received bilateral implants. Three of these patients received unilateral stimulation and experienced a $66 \%-100 \%$ reduction in seizure frequency. Patients without lesional mesial TLE received bilateral implants and were treated with unilateral stimulation $(\mathrm{n}=2,80 \%$ and $97 \%$ reduction in seizure frequency) or bilateral stimulation (nonresponder). The authors subsequently reported the results of their prospective, randomized double-blind study. ${ }^{15}$ The trial enrolled 16 patients with refractory TLE who underwent implantation of hippocampal leads and were randomized to stimulation on or off arms. While a lesional effect was noted, $50 \%$ of the treatment group experienced complete seizure freedom and $88 \%$ were considered responders. Velasco et al., for a period ranging from 18 months to 7 years, followed up nine patients who had undergone hippocampal DBS. ${ }^{68}$ The four patients with hippocampal sclerosis experienced a $50 \%-70 \%$ seizure reduction, whereas the five patients with nonlesional mesial TLE experienced $>95 \%$ seizure reduction. Not all studies have yielded such robust results. Tellez-Zenteno et al. reported on four patients with drug-resistant mesial TLE treated with left hippocampal DBS; median seizure reductions were a meager $15 \%$. $^{63}$

\section{Studies on Targeting the STN}

The STN is a highly vascular nucleus located between the zona incerta and the cerebral peduncle. Its afferent fibers chiefly include those from the cerebral cortex and the globus pallidus externa (GPe), as well as the centromedian/parafascicular nuclei. It projects mainly to the globus pallidus and substantia nigra reticulata $(\mathrm{SNr})$, though it also has connections with the striatum, substantia innominata, and cerebral cortex, among others ${ }^{51}$ Its utility in the treatment of epilepsy is still unclear, and additional trials are needed to determine which patients can most benefit from this target.

By far, the most well-studied indication for DBS in the STN is for movement disorders such as Parkinson's disease ${ }^{74}$ It has also been studied for the treatment of neuropsychiatric disorders such as severe obsessive-compulsive 
disorder. ${ }^{41}$ Several studies have examined its potential utility in the treatment of drug-resistant epilepsy. Chabardès et al. reported a mean seizure reduction of $64.2 \%$ experienced by four of five patients, whereas no effect was noted in the fifth. ${ }^{10}$ In another small cohort of three patients, Lee et al. noted mean seizure reductions of $49.1 \%$ after STN DBS. ${ }^{36}$ Additional small uncontrolled studies exist, ${ }^{26,71}$ though large randomized trials are needed to determine the efficacy of STN DBS for its utility in refractory epilepsy.

\section{Studies on Targeting the Cerebellum}

The cerebellum is situated caudal to the cerebrum. It is connected to the rest of the CNS by the three paired cerebellar peduncles. Cerebellar afferents arrive by way of the inferior (from inferior olivary complex, pons, dorsal spinocerebellar tract, and vestibular system), middle (corticopontine fibers), and superior cerebellar peduncles (ventral spinocerebellar tract). Efferents, mainly from the deep nuclei, leave via the inferior and superior cerebellar peduncles. ${ }^{56}$ The cerebellum is well described for its participation in motor control. However, emerging research also suggests that the cerebellum plays an important role in cognition and has been found to participate in cerebral association networks. ${ }^{8}$ While the cerebellum has the longest history in DBS for the treatment of epilepsy, results have been mixed. Therefore, stimulation of the cerebellum has fallen out of favor.

A study published in 1978 detailed the treatment of five drug-resistant epilepsy patients with bilateral cerebellar hemisphere stimulation. No observable decrease in seizure frequency was reported. ${ }^{65}$ In another study published in 1981, 14 epilepsy patients were treated with bilateral cerebellar hemisphere stimulation. ${ }^{4}$ The authors reported seizure elimination in five cases and a failure to significantly change seizure frequency in only three cases. A double-blind randomized pilot study treated five drugresistant epilepsy patients with bilateral cerebellar hemisphere stimulation. ${ }^{69}$ Patients initially randomized to the stimulator-off mode did not experience a reduction in seizures, whereas patients randomized to the stimulator-on mode had $33 \%$ seizure reduction. After a 6-month followup in which all patients received stimulation, the authors reported a mean seizure reduction of $41 \%$ compared to baseline. In a separate study of 12 patients with intractable epilepsy treated with cerebellar stimulation, no reduction in seizure frequency was reported at 6 months. ${ }^{75}$

\section{Responsive Neurostimulation}

Responsive neurostimulation (RNS) is a unique implantable electrical current delivery method that does not rely on continuous or predefined intermittent stimulation paradigms. The treating physician programs the RNS device to recognize electrocorticographic (ECoG) patterns unique to the patient that may occur prior to ictal onset. When the patient subsequently experiences similar ECoG activity, the device delivers a high-frequency stimulation impulse to either the cortical surface via subdural grids or the deep structures via depth electrodes (Fig. 2). This benefits the patient in several ways. Most obviously, it serves
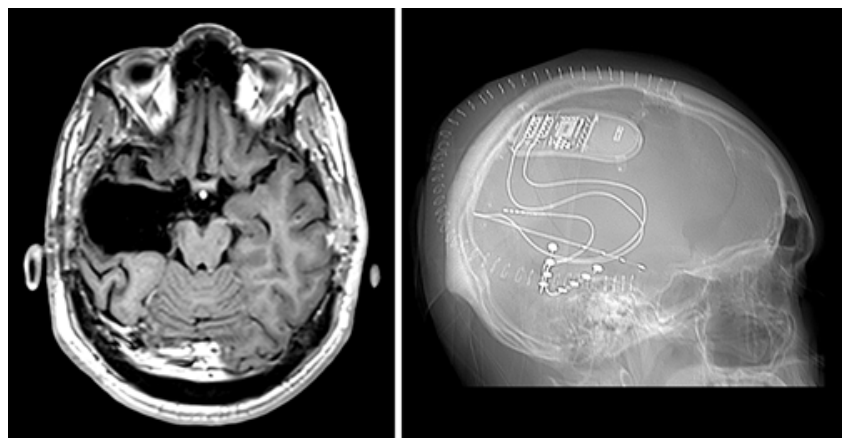

FIG. 2. Images obtained in a patient with disabling seizures who underwent intracranial electroencephalography monitoring and was found to have bitemporal epilepsy with $80 \%$ of the seizures originating from the right side. He underwent palliative right anteromesial temporal resection (left). After a 6-month seizure-free period, his seizures (of left temporal origin) resurfaced. He subsequently underwent implantation of the RNS NeuroPace system (right). For patients with drug-resistant epilepsy who are unable to undergo resective surgery of a seizure focus, DBS provides additional seizure relief. The neurostimulator is placed under the scalp after creating a small craniectomy to house the implant and is connected to two intracranial 4-contact depth or strip electrodes.

as immediate treatment for impending seizures rather than relying on timing as with an on/off stimulation paradigm. Because the system only fires when it detects aberrant ECoG activity, battery life is prolonged. Developed by NeuroPace, the RNS system was approved by the FDA in 2013 for the treatment of refractory partial seizures in adults. This was based on data obtained from the pivotal 2011 trial that demonstrated patients with drug-resistant epilepsy receiving RNS had, on average, $37.9 \%$ fewer seizures, compared to the sham group's decreased seizure rate of $17.3 \% .^{46}$ Importantly, quality of life also improved in these patients. Inclusion criteria were patient ages 18-70 years and three or more simple partial, complex partial, or secondarily generalized seizures each month despite a minimum of two AEDs. Patients were excluded if they experienced nonepileptic seizures, had primarily generalized seizures, had progressive CNS or another significant medical disorder, or had undergone a recent neurosurgical or VNS implant procedure. Long-term data are also available for RNS and are even more striking. A median seizure reduction of $53 \%$ was observed at 2 years in 230 patients.,27 Importantly, 44\% of participants have also reported meaningful improvement in quality of life at 2 years. ${ }^{44}$ At 8 years, median seizure reduction has been reported to be $73 \%$ (175 patients). ${ }^{23}$

\section{Complications of DBS}

When considering complications associated with DBS used to treat epilepsy, it is important to examine safety results obtained from the highest quality studies, including the SANTE trial. ${ }^{20}$ Long-term safety results from the SANTE trial showed that the most common adverse event associated with DBS was implantation site pain (23.6\%). Paresthesias were also common, occurring in $22.7 \%$ of patients. Implant site infection occurred in $12.7 \%$ of patients, and lead misplacement occurred in $8.2 \%$. Less common 
adverse events included dizziness (6.3\%), lead fracture (5.5\%), and lead migration (5.5\%). Overall, serious adverse events occurred in $33.6 \%$ of patients over 5 years, which includes $10 \%$ experiencing implant site infection and $8.2 \%$ with leads in an incorrect location. ${ }^{57}$ While the RNS NeuroPace system can utilize depth electrodes similar to those of traditional DBS devices, it differs significantly because the generator is implanted inside the cranial vault. This presents a number of potential disadvantages, including the need for access to the skull whenever the system must be replaced. In addition, any infection would take place closer to the brain and CSF spaces.

It is important to consider the possibility of exacerbating seizures or inducing new seizures when offering DBS as a treatment for epilepsy. A review of 2101 electrode placements across 16 reports revealed an incidence of newonset seizures in up to $13 \%$ of patients. ${ }^{12}$ At least $74 \%$ of seizures occurred around the time of electrode placement, with many patients experiencing intracranial hemorrhage. In this analysis, the authors estimated that DBS is associated with a $<2.4 \%(95 \%$ CI $1.7 \%-3.3 \%)$ risk of seizures and that the postprocedural risk of seizures from chronic DBS was approximately $0.5 \%$ (95\% CI $0.02 \%-1.0 \%) .{ }^{12} \mathrm{~A}$ separate report examined 161 patients who had 288 leads placed. ${ }^{54}$ Among these patients, $4.3 \%$ experienced seizures. The vast majority $(86 \%)$ of seizures occurred within 48 hours after lead implantation.

Deep brain stimulation appears to be a relatively safe procedure, with most complications appearing during or around the time of electrode implantation. This is not to say, however, that implantation techniques cannot be improved upon. As an example, in 2015 Van Gompel et al. released a report that described a novel trajectory to the ANT that may be safer and may provide a method of assessing the Papez circuit to provide electrophysiological confirmation of lead placement intraoperatively. ${ }^{66}$ Emerging technologies such as near-infrared spectroscopy and intraoperative MRI may increase the accuracy of probe placement and decrease complications. ${ }^{9,22}$

\section{Summary}

Deep brain stimulation is a safe and efficacious treatment for drug-resistant epilepsy. It is effective in reducing seizure frequency in patients who otherwise have no other treatment options. Some patients treated with DBS can attain seizure freedom. The targets chosen for DBS vary and mainly include the ANT, the CMT, and the hippocampus. Specifically, patients with partial seizures or secondarily generalized seizures may benefit more from ANT DBS, whereas those with generalized epilepsy such as in Lennox-Gastaut syndrome may benefit more from CMT DBS. Individuals with mesial TLE may benefit from hippocampal DBS. As hardware and implantation techniques continue to improve, the safety of these procedures will also improve. Perhaps most importantly, additional large randomized double-blind trials will help to solidify the efficacy of DBS and increase its utilization.

\section{References}

1. Akman T, Erken H, Acar G, Bolat E, Kizilay Z, Acar F, et al:
Effects of the hippocampal deep brain stimulation on cortical epileptic discharges in penicillin-induced epilepsy model in rats. Turk Neurosurg 21:1-5, 2011

2. Andrade DM, Zumsteg D, Hamani C, Hodaie M, Sarkissian S, Lozano AM, et al: Long-term follow-up of patients with thalamic deep brain stimulation for epilepsy. Neurology 66:1571-1573, 2006

3. Bergey GK, Morrell MJ, Mizrahi EM, Goldman A, King-Stephens D, Nair D, et al: Long-term treatment with responsive brain stimulation in adults with refractory partial seizures. Neurology 84:810-817, 2015

4. Bidziński J, Bacia T, Ostrowski K, Czarkwiani L: [Effect of cerebellar cortical electrostimulation on the frequency of epileptic seizures in severe forms of epilepsy.] Neurol Neurochir Pol 15:605-609, 1981 (Polish)

5. Boëx C, Seeck M, Vulliémoz S, Rossetti AO, Staedler C, Spinelli L, et al: Chronic deep brain stimulation in mesial temporal lobe epilepsy. Seizure 20:485-490, 2011

6. Bondallaz P, Boëx C, Rossetti AO, Foletti G, Spinelli L, Vulliemoz S, et al: Electrode location and clinical outcome in hippocampal electrical stimulation for mesial temporal lobe epilepsy. Seizure 22:390-395, 2013

7. Boon P, Vonck K, De Herdt V, Van Dycke A, Goethals M, Goossens L, et al: Deep brain stimulation in patients with refractory temporal lobe epilepsy. Epilepsia 48:1551-1560, 2007

8. Buckner RL: The cerebellum and cognitive function: 25 years of insight from anatomy and neuroimaging. Neuron 80:807-815, 2013

9. Chabardes S, Isnard S, Castrioto A, Oddoux M, Fraix V, Carlucci L, et al: Surgical implantation of STN-DBS leads using intraoperative MRI guidance: technique, accuracy, and clinical benefit at 1-year follow-up. Acta Neurochir (Wien) 157:729-737, 2015

10. Chabardès S, Kahane P, Minotti L, Koudsie A, Hirsch E, Benabid AL: Deep brain stimulation in epilepsy with particular reference to the subthalamic nucleus. Epileptic Disord 4 (Suppl 3):S83-S93, 2002

11. Cohen-Gadol AA, Wilhelmi BG, Collignon F, White JB, Britton JW, Cambier DM, et al: Long-term outcome of epilepsy surgery among 399 patients with nonlesional seizure foci including mesial temporal lobe sclerosis. J Neurosurg 104:513-524, 2006

12. Coley E, Farhadi R, Lewis S, Whittle IR: The incidence of seizures following deep brain stimulating electrode implantation for movement disorders, pain and psychiatric conditions. Br J Neurosurg 23:179-183, 2009

13. Cukiert A, Cukiert CM, Burattini JA, Lima AM: Seizure outcome after battery depletion in epileptic patients submitted to deep brain stimulation. Neuromodulation 18:439441, 2015

14. Cukiert A, Cukiert CM, Burattini JA, Lima AM: Seizure outcome after hippocampal deep brain stimulation in a prospective cohort of patients with refractory temporal lobe epilepsy. Seizure 23:6-9, 2014

15. Cukiert A, Cukiert CM, Burattini JA, Mariani PP, Bezerra DF: Seizure outcome after hippocampal deep brain stimulation in patients with refractory temporal lobe epilepsy: a prospective, controlled, randomized, double-blind study. Epilepsia 58:1728-1733, 2017

16. DeGiorgio CM, Schachter SC, Handforth A, Salinsky M, Thompson J, Uthman B, et al: Prospective long-term study of vagus nerve stimulation for the treatment of refractory seizures. Epilepsia 41:1195-1200, 2000

17. Devinsky O, Marsh E, Friedman D, Thiele E, Laux L, Sullivan J, et al: Cannabidiol in patients with treatment-resistant epilepsy: an open-label interventional trial. Lancet Neurol 15:270-278, 2016

18. Feldmann M, Asselin MC, Liu J, Wang S, McMahon A, An- 
ton-Rodriguez J, et al: P-glycoprotein expression and function in patients with temporal lobe epilepsy: a case-control study. Lancet Neurol 12:777-785, 2013

19. Fiest KM, Sauro KM, Wiebe S, Patten SB, Kwon CS, Dykeman J, et al: Prevalence and incidence of epilepsy: a systematic review and meta-analysis of international studies. Neurology 88:296-303, 2017

20. Fisher R, Salanova V, Witt T, Worth R, Henry T, Gross R, et al: Electrical stimulation of the anterior nucleus of thalamus for treatment of refractory epilepsy. Epilepsia 51:899-908, 2010

21. Fisher RS, Uematsu S, Krauss GL, Cysyk BJ, McPherson R, Lesser RP, et al: Placebo-controlled pilot study of centromedian thalamic stimulation in treatment of intractable seizures. Epilepsia 33:841-851, 1992

22. Giller CA, Liu H, German DC, Kashyap D, Dewey RB: A stereotactic near-infrared probe for localization during functional neurosurgical procedures: further experience. J Neurosurg 110:263-273, 2009

23. Gwinn R, Morrell M: Long-term safety and efficacy of responsive brain stimulation in adults with medically intractable partial onset seizures, presented at the 71st Annual Meeting of the American Epilepsy Society, 2017 (Abstract) (https://www.aesnet.org/meetings_events/annual_meeting_ abstracts/view/345081) [Accessed May 30, 2018]

24. Hamani C, Hodaie M, Chiang J, del Campo M, Andrade DM, Sherman D, et al: Deep brain stimulation of the anterior nucleus of the thalamus: effects of electrical stimulation on pilocarpine-induced seizures and status epilepticus. Epilepsy Res 78:117-123, 2008

25. Handforth A, DeGiorgio CM, Schachter SC, Uthman BM, Naritoku DK, Tecoma ES, et al: Vagus nerve stimulation therapy for partial-onset seizures: a randomized active-control trial. Neurology 51:48-55, 1998

26. Handforth A, DeSalles AA, Krahl SE: Deep brain stimulation of the subthalamic nucleus as adjunct treatment for refractory epilepsy. Epilepsia 47:1239-1241, 2006

27. Heck CN, King-Stephens D, Massey AD, Nair DR, Jobst $\mathrm{BC}$, Barkley GL, et al: Two-year seizure reduction in adults with medically intractable partial onset epilepsy treated with responsive neurostimulation: final results of the RNS System Pivotal trial. Epilepsia 55:432-441, 2014

28. Hodaie M, Wennberg RA, Dostrovsky JO, Lozano AM: Chronic anterior thalamus stimulation for intractable epilepsy. Epilepsia 43:603-608, 2002

29. Jankowski MM, Ronnqvist KC, Tsanov M, Vann SD, Wright NF, Erichsen JT, et al: The anterior thalamus provides a subcortical circuit supporting memory and spatial navigation. Front Syst Neurosci 7:45, 2013

30. Jin H, Li W, Dong C, Wu J, Zhao W, Zhao Z, et al: Hippocampal deep brain stimulation in nonlesional refractory mesial temporal lobe epilepsy. Seizure 37:1-7, 2016

31. Jobst BC, Cascino GD: Resective epilepsy surgery for drugresistant focal epilepsy: a review. JAMA 313:285-293, 2015

32. Kerrigan JF, Litt B, Fisher RS, Cranstoun S, French JA, Blum DE, et al: Electrical stimulation of the anterior nucleus of the thalamus for the treatment of intractable epilepsy. Epilepsia 45:346-354, 2004

33. Kim HY, Hur YJ, Kim HD, Park KM, Kim SE, Hwang TG: Modification of electrophysiological activity pattern after anterior thalamic deep brain stimulation for intractable epilepsy: report of 3 cases. J Neurosurg 126:2028-2035, 2017

34. Kim SH, Lim SC, Kim J, Son BC, Lee KJ, Shon YM: Longterm follow-up of anterior thalamic deep brain stimulation in epilepsy: a 11-year, single center experience. Seizure 52:154161, 2017

35. Kwan P, Arzimanoglou A, Berg AT, Brodie MJ, Allen Hauser W, Mathern G, et al: Definition of drug resistant epilepsy: consensus proposal by the ad hoc Task Force of the ILAE
Commission on Therapeutic Strategies. Epilepsia 51:1069_ 1077,2010

36. Lee KJ, Jang KS, Shon YM: Chronic deep brain stimulation of subthalamic and anterior thalamic nuclei for controlling refractory partial epilepsy. Acta Neurochir Suppl 99:87-91, 2006

37. Lee KJ, Shon YM, Cho CB: Long-term outcome of anterior thalamic nucleus stimulation for intractable epilepsy. Stereotact Funct Neurosurg 90:379-385, 2012

38. Lim SN, Lee ST, Tsai YT, Chen IA, Tu PH, Chen JL, et al: Electrical stimulation of the anterior nucleus of the thalamus for intractable epilepsy: a long-term follow-up study. Epilepsia 48:342-347, 2007

39. Lim SN, Lee ST, Tsai YT, Chen IA, Tu PH, Chen JL, et al: Long-term anterior thalamus stimulation for intractable epilepsy. Chang Gung Med J 31:287-296, 2008

40. Lozano AM, Eltahawy H: How does DBS work? Suppl Clin Neurophysiol 57:733-736, 2004

41. Mallet L, Polosan M, Jaafari N, Baup N, Welter ML, Fontaine $\mathrm{D}$, et al: Subthalamic nucleus stimulation in severe obsessive-compulsive disorder. N Engl J Med 359:2121-2134, 2008

42. Martin RC, Kretzmer T, Palmer C, Sawrie S, Knowlton R, Faught E, et al: Risk to verbal memory following anterior temporal lobectomy in patients with severe left-sided hippocampal sclerosis. Arch Neurol 59:1895-1901, 2002

43. McIntyre CC, Savasta M, Kerkerian-Le Goff L, Vitek JL: Uncovering the mechanism(s) of action of deep brain stimulation: activation, inhibition, or both. Clin Neurophysiol 115:1239-1248, 2004

44. Meador KJ, Kapur R, Loring DW, Kanner AM, Morrell MJ: Quality of life and mood in patients with medically intractable epilepsy treated with targeted responsive neurostimulation. Epilepsy Behav 45:242-247, 2015

45. Mirski MA, Rossell LA, Terry JB, Fisher RS: Anticonvulsant effect of anterior thalamic high frequency electrical stimulation in the rat. Epilepsy Res 28:89-100, 1997

46. Morrell MJ: Responsive cortical stimulation for the treatment of medically intractable partial epilepsy. Neurology 77:1295-1304, 2011

47. Morris GL III, Mueller WM: Long-term treatment with vagus nerve stimulation in patients with refractory epilepsy. The Vagus Nerve Stimulation Study Group E01-E05. Neurology 53:1731-1735, 1999

48. Murray CJ, Vos T, Lozano R, Naghavi M, Flaxman AD, Michaud C, et al: Disability-adjusted life years (DALYs) for 291 diseases and injuries in 21 regions, 1990-2010: a systematic analysis for the Global Burden of Disease Study 2010. Lancet 380:2197-2223, 2012

49. Neal EG, Chaffe H, Schwartz RH, Lawson MS, Edwards N, Fitzsimmons G, et al: The ketogenic diet for the treatment of childhood epilepsy: a randomised controlled trial. Lancet Neurol 7:500-506, 2008

50. Osorio I, Overman J, Giftakis J, Wilkinson SB: High frequency thalamic stimulation for inoperable mesial temporal epilepsy. Epilepsia 48:1561-1571, 2007

51. Parent A, Hazrati LN: Functional anatomy of the basal ganglia. II. The place of subthalamic nucleus and external pallidum in basal ganglia circuitry. Brain Res Brain Res Rev 20:128-154, 1995

52. Pasnicu A, Denoyer Y, Haegelen C, Pasqualini E, Biraben A: Modulation of paroxysmal activity in focal cortical dysplasia by centromedian thalamic nucleus stimulation. Epilepsy Res 104:264-268, 2013

53. Picot MC, Baldy-Moulinier M, Daurès JP, Dujols P, Crespel A: The prevalence of epilepsy and pharmacoresistant epilepsy in adults: a population-based study in a Western European country. Epilepsia 49:1230-1238, 2008

54. Pouratian N, Reames DL, Frysinger R, Elias WJ: Compre- 
hensive analysis of risk factors for seizures after deep brain stimulation surgery. Clinical article. J Neurosurg 115:310315,2011

55. Saalmann YB: Intralaminar and medial thalamic influence on cortical synchrony, information transmission and cognition. Front Syst Neurosci 8:83, 2014

56. Salamon N, Sicotte N, Drain A, Frew A, Alger JR, Jen J, et al: White matter fiber tractography and color mapping of the normal human cerebellum with diffusion tensor imaging. J Neuroradiol 34:115-128, 2007

57. Salanova V, Witt T, Worth R, Henry TR, Gross RE, Nazzaro JM, et al: Long-term efficacy and safety of thalamic stimulation for drug-resistant partial epilepsy. Neurology 84:10171025,2015

58. Schmidt D, Stavem K: Long-term seizure outcome of surgery versus no surgery for drug-resistant partial epilepsy: a review of controlled studies. Epilepsia 50:1301-1309, 2009

59. Shah A, Jhawar SS, Goel A: Analysis of the anatomy of the Papez circuit and adjoining limbic system by fiber dissection techniques. J Clin Neurosci 19:289-298, 2012

60. Son BC, Shon YM, Choi JG, Kim J, Ha SW, Kim SH, et al: Clinical outcome of patients with deep brain stimulation of the centromedian thalamic nucleus for refractory epilepsy and location of the active contacts. Stereotact Funct Neurosurg 94:187-197, 2016

61. Tang F, Hartz AMS, Bauer B: Drug-resistant epilepsy: multiple hypotheses, few answers. Front Neurol 8:301, 2017

62. Téllez-Zenteno JF, Dhar R, Wiebe S: Long-term seizure outcomes following epilepsy surgery: a systematic review and meta-analysis. Brain 128:1188-1198, 2005

63. Tellez-Zenteno JF, McLachlan RS, Parrent A, Kubu CS, Wiebe S: Hippocampal electrical stimulation in mesial temporal lobe epilepsy. Neurology 66:1490-1494, 2006

64. Valentín A, García Navarrete E, Chelvarajah R, Torres C, Navas M, Vico L, et al: Deep brain stimulation of the centromedian thalamic nucleus for the treatment of generalized and frontal epilepsies. Epilepsia 54:1823-1833, 2013

65. Van Buren JM, Wood JH, Oakley J, Hambrecht F: Preliminary evaluation of cerebellar stimulation by double-blind stimulation and biological criteria in the treatment of epilepsy. J Neurosurg 48:407-416, 1978

66. Van Gompel JJ, Klassen BT, Worrell GA, Lee KH, Shin C, Zhao CZ, et al: Anterior nuclear deep brain stimulation guided by concordant hippocampal recording. Neurosurg Focus 38(6):E9, 2015

67. Velasco AL, Velasco F, Jiménez F, Velasco M, Castro G, Carrillo-Ruiz JD, et al: Neuromodulation of the centromedian thalamic nuclei in the treatment of generalized seizures and the improvement of the quality of life in patients with Lennox-Gastaut syndrome. Epilepsia 47:1203-1212, 2006
68. Velasco AL, Velasco F, Velasco M, Trejo D, Castro G, Carrillo-Ruiz JD: Electrical stimulation of the hippocampal epileptic foci for seizure control: a double-blind, long-term follow-up study. Epilepsia 48:1895-1903, 2007

69. Velasco F, Carrillo-Ruiz JD, Brito F, Velasco M, Velasco AL, Marquez I, et al: Double-blind, randomized controlled pilot study of bilateral cerebellar stimulation for treatment of intractable motor seizures. Epilepsia 46:1071-1081, 2005

70. Velasco F, Velasco M, Velasco AL, Jimenez F, Marquez I, Rise M: Electrical stimulation of the centromedian thalamic nucleus in control of seizures: long-term studies. Epilepsia 36:63-71, 1995

71. Vesper J, Steinhoff B, Rona S, Wille C, Bilic S, Nikkhah $\mathrm{G}$, et al: Chronic high-frequency deep brain stimulation of the STN/SNr for progressive myoclonic epilepsy. Epilepsia 48:1984-1989, 2007

72. Vining EP, Freeman JM, Ballaban-Gil K, Camfield CS, Camfield PR, Holmes GL, et al: A multicenter study of the efficacy of the ketogenic diet. Arch Neurol 55:1433-1437, 1998

73. Vonck K, Boon P, Achten E, De Reuck J, Caemaert J: Longterm amygdalohippocampal stimulation for refractory temporal lobe epilepsy. Ann Neurol 52:556-565, 2002

74. Weaver FM, Follett K, Stern M, Hur K, Harris C, Marks WJ $\mathrm{Jr}$, et al: Bilateral deep brain stimulation vs best medical therapy for patients with advanced Parkinson disease: a randomized controlled trial. JAMA 301:63-73, 2009

75. Wright GD, McLellan DL, Brice JG: A double-blind trial of chronic cerebellar stimulation in twelve patients with severe epilepsy. J Neurol Neurosurg Psychiatry 47:769-774, 1984

\section{Disclosures}

The authors report no conflict of interest concerning the materials or methods used in this study or the findings specified in this paper.

\section{Author Contributions}

Conception and design: Mittal. Acquisition of data: Klinger. Analysis and interpretation of data: both authors. Drafting the article: both authors. Critically revising the article: Mittal. Reviewed submitted version of manuscript: both authors. Approved the final version of the manuscript on behalf of both authors: Mittal. Administrative/technical/material support: Mittal. Study supervision: Mittal.

\section{Correspondence}

Sandeep Mittal: Wayne State University, Detroit, MI. smittal@ med.wayne.edu. 